\title{
Jurnal Teknik Mesin
}

ISSN: $2089-4880$

http://ejournal.itp.or.id/index.php/tmesin/

\section{Effect of Cyclone Diffuser Swirl throughout the $30 \mathrm{~mm}$ On Liquid Jet Gas Pump (Application on Frying chips Pineapple)}

\author{
Pengaruh Pusaran Cyclone Diffuser Sepanjang $30 \mathrm{~mm}$ \\ Pada Liquid Jet Gas Pump \\ (Aplikasi Pada Penggorengan Kripik Nanas)
}

\author{
Eswanto \\ Department of Mechanical Engineering, Institut Teknologi Medan \\ Jl.Gedung Arca No. 52 Medan, Indonesia
}

\begin{abstract}
Received 12 October 2016; Revised 23 Oktober 2016; Accepted 27 Oktober 2016, Published 31 Oktober 2016 Academic Editor: Asmara Yanto (asmarayanto@yahoo.com)

Correspondence should be addressed to eswanto@itm.ac.id

Copyright (C) 2016 Eswanto. This is an open access article distributed under the Creative Commons Attribution License.
\end{abstract}

\begin{abstract}
Pineapple is a plant that is widely available in Indonesia and fruit favored by the public. Some areas in North Sumatra as langkat, Binjai, Berastagi, Siborong-borong many supply pineapples to the city field, so if at the time of pineapple fruit season arrives, the city became a flood pineapple field and consequently if the fruit is not sold will be rotten. Seeing this need to utilize technology in order not rotten pineapple and wasted, therefore there is need to do an experiment to make a pineapple into chips with technology liguid jet gas pump (LJGP) which method a way with a vacuum system. From the problems necessary to study to get the best vacuum LJGP tool is one of them by adding a Cyclone vortex diffuser models. The purpose of this study is to obtain the best vacuum as well as the efficiency of LJGP that can be used in frying applications pineapple crisps vacuum method along the vortex diffuser $30 \mathrm{~mm}$. The research method with experiments involving fluid water and air, by adding a Cyclone vortex Diffuser models in LJGP tool as long $30 \mathrm{~mm}$. The observed data is the primary flow rate (primary flow / motive flow) is $0.32 \mathrm{~L} / \mathrm{s}$, up to $0.44 \mathrm{~L} / \mathrm{s}$ and discharge secondary flow (secondary flow) ranged from $0.04 \mathrm{~L} / \mathrm{s}$ to $0.2 \mathrm{~L} / \mathrm{s}$. As for the water to circulate fluid LJGP, used types of centrifugal pumps with a capacity of $340 \mathrm{~L} / \mathrm{min}$. From the research that has been done shows that the more points cyclone vortex diffuser, the secondary pressure will increase. The maximum secondary pressure in the cyclone vortex diffuser length 30 mm which is $150215 \mathrm{kPa}$, with secondary pressure maximum of 12 GPM is present in 1,367 $\mathrm{kPa}$. This condition is informed that the use of models in the vortex of Cyclone Diffuser LJGP tool is in need to improve the vacuum system for LJGP.
\end{abstract}

Keywords: Cyclone, pineapple, vacuum, water, air, LJGP.

\section{Pendahuluan}

Dalam memanfaatkan hasil perkebunan masyarakat dibutuhkan teknologi dan ide-ide kreatif agar hasil yang didapatkan menjadi nilai jual yang tinggi. Nanas merupakan tanaman perkebunan yang banyak terdapat di Indonesia dan buahnya disukai oleh masyarakat. Beberapa daerah di Sumatera Utara seperti Langkat, Binjai, Berastagi, Siborong-borong banyak memasok buah nanas ke Medan, sehingga jika pada saat musim buah nanas tiba kota Medan menjadi banjir nanas dan akibatnya jika buah tidak laku dijual akan menjadi busuk. Melihat hal tersebut perlu teknologi untuk memanfaatkan nanas agar tidak busuk dan terbuang, maka dari itu penelitian terkait untuk membuat nanas menjadi kripik dengan teknologi Liguid Jet Gas Pump (LJGP) yaitu 
metode vakum merupakan suatu kebutuhan. Dari permasalahan tersebut perlu dilakukan kajian untuk mendapatkan hasil kevakuman terbaik alat LJGP yaitu salah satunya dengan menambahkan model Cyclone Diffuser.

Cyclone Diffuser yang akan dibuat berbentuk spiral untuk menjadikan aliran berubah dari laminar manjadi turbulen dengan harapan semakin kuat kevakuman yang didapatkan dari alat LJGP tersebut. Dimana LJGP yang tersusun dari komponen utama yaitu Nozzle, throat, section chamber, diffuser. Dengan tingkat kevakuman yang baik, maka proses penggorengan kripik nanas menjadi lebih baik pula, sehingga nanas dapat termanfaatkan dengan nilai jual yang tinggi.

Diffuser adalah tabung berbentuk kerucut yang sisi bagian atas digunakan untuk memperluas aliran dari laras throat ke dalam sisi keluar diffuser. Panjang diffuser dapat menentukan seberapa besar tekanan pompa, khususnya dibagian sisi masuk yang terkoneksi dengan throat. Pada bagian sudut diffuser yang mempunyai diameter kecil disisi masuknya (bagian yang tersambung dengan throat) diperkirakan mempunyai tekanan yang lebih baik. Sedangkan pada diffuser saluran keluar banyak energi kinetik yang dirubah menjadi bentuk energi potensial.

Pada penelitian ini Diffuser yang dibuat difungsikan untuk mengubah bentuk dari energi energi kecepatan aliran menjadi energi tekanan aliran. Perubahan bentuk energi ini dilakukan secara bertahap. Berdasarkan proses konversi yang terjadi di dalam diffuser, perubahan luas penampang dibuat untuk mendapatkan efisiensi dari diffuser ini yang lebih baik, disamping itu pada diffuser prinsipnya yang harus dihindari adalah gradien tekanan yang besar pada diffuser.

Sharma [1] melakukan pengujian untuk profil sudut kontaksi terhadap kinerja ejector cair-gas. Profil kontaksi nozzle yang diuji adalah conical, circular, dan elliptical Pada ekepsrimen ini nozzle dengan profil elliptical memberikan pressure ratio dan efisiensi tertinggi dibandingkan dari profil kontraksi nozzle conical, dan circular.

Yadav dan Patwardhan [2] mengemukakan bahwa geometri optimum diffuser adalah 40 hingga 100 , dengan panjangnya 4 sampai 8 diameter throat. Neve [3] menyampaikan bahwa geometri optimum adalah 6,80, dengan rasio luas penampang sebesar 5,6. Sedangkan Owen [4] menyatakan Geometri optimum diffuser dicapai pada sudut 700 dengan rasio luas penampang 1 berbanding 9. Fenomena aliran melintas diffuser untuk aliran berfasa ganda, gas dan cairan fenomena yang terjadi berbeda dengan fenomena yang terjadi pada aliran berfasa tunggal. Pengaruh void fraction didalam cairan merupakan variabel yang dominan mempengaruhi kinerja diffuser [3].

Di bagian lain terkait dengan penelitian LJGP ini, Eswanto [5] melakukan penelitian tentang Efek Variasi debit aliran primer dan sekunder dalam mencapai kevakuman pada Liquid Jet Gas Pump, hasil yang diperoleh menjelaskan bahwa Peningkatan debit aliran sekunder menyebabkan penurunan kecepatan aliran motive pada sisi keluar nosel dengan dimensi throat konstan 3.5dT. Menurunnya kecepatan tersebut akan diiringi dengan menurunnya tekanan vakum. Sementara itu bertambahnya debit aliran primer menyebabkan terjadinya peningkatan tekanan vakum dan debit aliran sekunder, dan dalam penelitiannnya yang lain masih terkait dengan LJGP Eswanto [6] melaporkan bahwa dengan Panjang Throat $30,45 \mathrm{~mm}$ terjadi peningkatan rasio aliran yang menyebabkan terjadinya penurunan rasio tekanan sehingga kecepatan aliran motive menurun, efesiensi tertinggi diperolah sebesar $10,543 \%$ dengan tingkat kevakuman mencapai $85,828 \mathrm{kPa}$.

\section{Bahan dan Metode}

Metode penelitian yang dilakukan adalah metode eksperimen yang dilaksanakan di Laboratorium Fenomena Dasar Mesin Institut Teknologi Medan, selanjutnya pada akhir penelitian membuat korelasi dengan hasil penelitian sebelumnya. Secara umum ada empat tahapan utama dalam penelitian yang laksanakan dengan judul: "Pengaruh Pusaran Cyclone Diffuser Sepanjang $30 \mathrm{~mm}$ Pada Liquid Jet Gas Pump (Aplikasi Pada Penggorengan Kripik Nanas)". Dalam pengukuran untuk mendapatkan data hasil riset digunakan alat ukur yang disesuaikan dengan kebutuhan pengamatan, alat ukur tersebut diantaranya adalah: flow meter udara, flow meter air, manometer U, penggaris Tahapantahapan tersebut yaitu tahap persiapan, tahap kalibrasi, pengujian dan penyelesaian. Tabel 1 adalah parameter yang digunakan pada penelitian ini.

Tabel 1. Parameter penelitian

\begin{tabular}{ll}
\hline Parameter & Unit \\
\hline Panjang cyclone diffuser & $30 \mathrm{~mm}$ \\
\hline Diameter throat & $24 \mathrm{~mm}$ \\
\hline Debit aliran primer & $4,8,12,16,20 \mathrm{Gpm}$ \\
\hline Debit aliran sekunder & $10,15,20,25,30$ \\
\hline
\end{tabular}




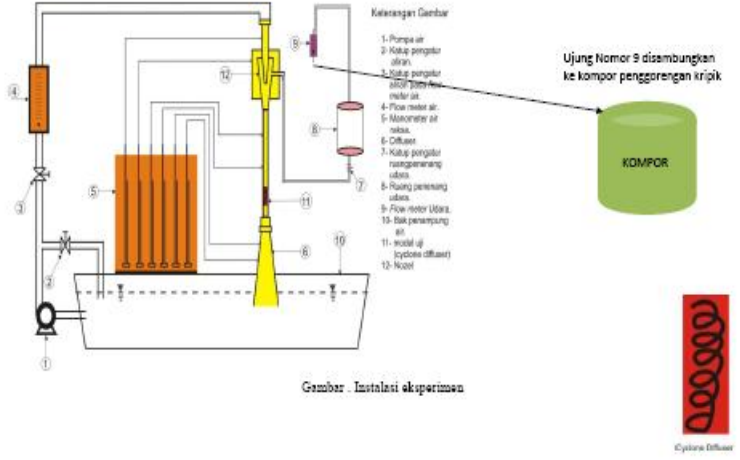

Gambar 1. Instalasi Alat Uji

\section{Hasil dan Pembahasan}

Hasil penelitian yang ditunjukkan pada Gambar 2 merupakan hasil pengukuran tekanan motive (Pm) pada flow meter air dan debit aliran sekunder (QG) pada flow meter udara dengan pusaran cyclone diffuser $30 \mathrm{~mm}$, dengan memberikan variasi debit motive, dan aliran sekunder yang terdapat dibagian flow udara.

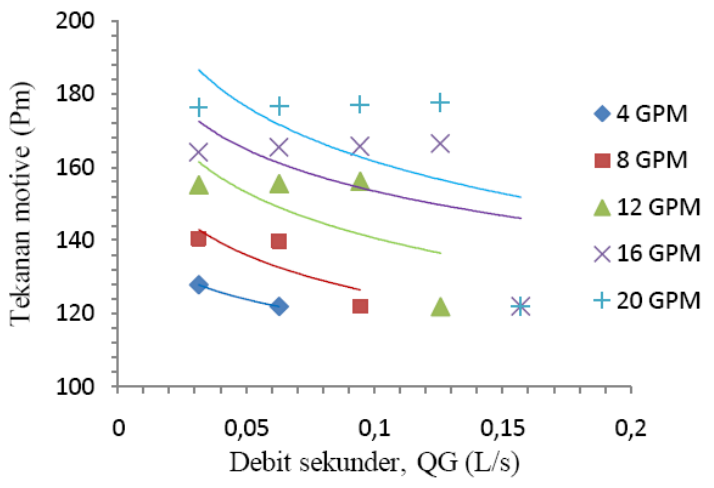

Gambar 2. Grafik hubungan Debit sekunder dengan Tekanan Motive

Dari hasil pengukuran dan analisa data dapat di informasikan bahwa ketika ada perlakuan peningkatan debit aliran sekunder pada debit motive yang sama, kondisi tersebut menyebabkan terjadinya peningkatan tekanan motive. Hal ini terjadi karena kecepatan aliran yang melewati pusaran cyclone diffuser mengalami penurunan seiring dengan meningkatnya debit aliran sekunder yaitu pada bagian sisi flow udara, sehingga terjadi peningkatan tekanan motive. Semakin bertambanya titik pusaran pada cyclone diffuser yang menyebabkan kecepatan aliran pada sisi keluar cyclone diffuser meningkat, sehingga berakibat pada penurunan tekanan vakum. Tekanan vakum yang menurun akan menyebabkan debit aliran sekunder juga menurun dan jika semakin tinggi debit sekunder yang masuk ke dalam cyclone diffuser $30 \mathrm{~mm}$ melalui section chamber dan throat maka tekanan motive yang dihasilkan semakin meningkat. Tekanan motive maksimum hasil pengamatan cyclone diffuser $30 \mathrm{~mm}$ terdapat pada 25 GPM yaitu $205,137 \mathrm{kPa}$, dan tekanan motive minimum terdapat pada 5 GPM yaitu $155.231 \mathrm{kPa}$.

Hasil pengolahan data yang disajikan pada gambar 3 adalah hasil pengukuran rasio aliran dengan tekanan sekunder dengan panjang cyclone diffuser $30 \mathrm{~mm}$, rasio aliran yang dimaksud dalam penelitian ini adalah rasio aliran pada bagian air dan udara. Dari Gambar 3 terlihat bahwa semakin tinggi rasio aliran pada cyclone diffuser $30 \mathrm{~mm}$ maka semakin banyak pula titik pusaran cyclone diffuser yang dihasilkan, sehingga berdampak terhadap tekanan sekunder yang dihasilkan yaitu tekanan sekunder akan semakin meningkat. Tekanan sekunder maksimum yang dihasilkan pada cyclone diffuser $30 \mathrm{~mm}$ yaitu sebesar 150.215 $\mathrm{kPa}$, dengan tekanan sekunder minimum terdapat pada 12 GPM yaitu $1.367 \mathrm{kPa}$.

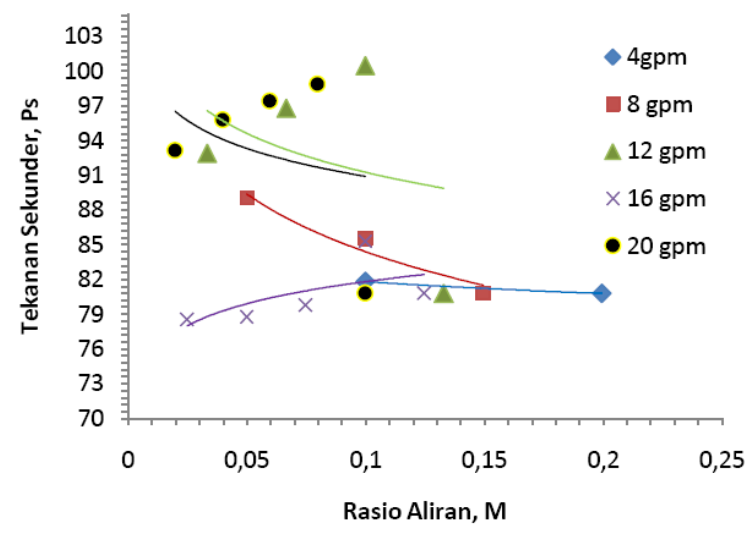

Gambar 3. Grafik hubungan Rasio Aliran dengan Tekanan Sekunder

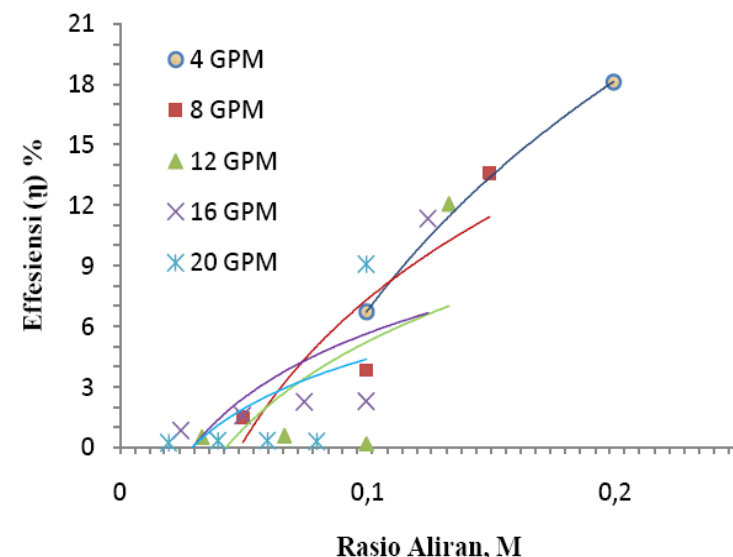

Gambar 4. Grafik hubungan Rasio Aliran dengan Efesiensi

Pada Gambar 4 adalah hasil pengukuran rasio aliran (M) terhadap effesiensi dengan variasi titik pusaran cyclone diffuser. Dari pengukuran yang telah dilaksanakan dan dituangkan ke dalam gambar 4 terlihat bahwa 
debit motive yang tinggi cenderung memberikan informasi terkait nilai efisiensi yang lebih baik pada semua tingkat rasio aliran. Efesiensi yang baik tersebut adalah adanya peningkatan rata-rata pada setiap line pada grafik yang ditunjukkan (Gambar 4). Dalam hal ini efisiensi meningkat pada seluruh variasi debit motive terhadap penurunan rasio aliran. Efesiensi maksimum pada pengujian cyclone diffuser terlihat pada gambar 4. Yaitu sebesar $18,11 \%$ pada debit motive 5 dengan tingkat kevakuman mencapai $80.79 \mathrm{kPa}$, kecendrungan efesiensi meningkat pada seluruh variasi debit motive terhadap penurunan rasio aliran, sedangkan bertambahnya titik pada pusaran cyclone diffuer model cendrung menyebabkan penurunan efesiensi pada semua tingkat rasio aliran hal tersebut kemungkinan karena adanya aliran turbulensi.

\section{Simpulan}

Dari hasil penelitian yang telah dilakukan yaitu semakin banyak titik pusaran cyclone diffuser maka tekanan sekunder akan semakin meningkat. Tekanan sekunder maksimum pada panjang cyclone diffuser $30 \mathrm{~mm}$ yaitu 150.215 $\mathrm{kPa}$, dengan tekanan sekunder maksimum terdapat pada 12 GPM yaitu $1.367 \mathrm{kPa}$, sedangkan di sisi lain untuk tekanan motive maksimum yaitu terdapat pada 25 GPM sebesar $205,137 \mathrm{kPa}$, dan tekanan motive minimum terdapat pada 5 GPM yaitu $155.231 \mathrm{kPa}$. Sedangkan efesiensinya didapat sebesar $18,11 \%$.

\section{Referensi}

[1] V. P. Sharma, S. Kusmaraswamy and A. Mani, "Effect of Various Nozzle Profiles on Performance of a Two Phase Flow Jet Pump," Engineering and Technology, pp. 546-552, 2012.

[2] R. L. Yadav and A. W. Patwardhan, "Design Aspects of Ejectors: Effects of Suction Chamber Geometry," Chemical Engineering Science, 63:3886-3897, 2008.

[3] R. S. Neve, "Diffuser Performance in Two-Phase Jet Pumps," International Journal of Multiphase Flow, vol. 17, pp. 267-272, 1991.

[4] I. Owen, A. Abdul-Ghani, and A. M. Amini, "Diffusing a homogenized twophase flow," International Journal of
Multiphase Flow, vol. 18, pp. 531-540, 1992.

[5] Eswanto, "Efek Variasi Debit Aliran Primer Dan Skunder Dalam Mencapai Kevakuman Pada Liquid Jet Gas Pump," Jurnal Momentum ITP Padang, vol.18, no.1, hal. 133-138, 2015.

[6] Eswanto, "Effect diameter of throat 8, 7 $\mathrm{mm}$ in improving performance liquid jet gas pump," IJRAET Int.Journal, vol. 2, Issue. 3, May 2016; pp. 57-60, www.engineeringresearchjournal.com. 